\title{
Diagnostic and prognostic value of interleukin-6, pentraxin 3, and procalcitonin levels among sepsis and septic shock patients: a prospective controlled study according to the Sepsis-3 definitions
}

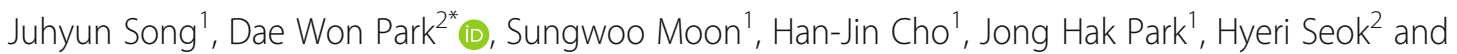 \\ Won Seok Choi ${ }^{2}$
}

\begin{abstract}
Background: This study investigated the clinical value of interleukin-6 (IL-6), pentraxin 3 (PTX3), and procalcitonin (PCT) in patients with sepsis and septic shock diagnosed according to the Third International Consensus Definitions for Sepsis and Septic Shock (Sepsis-3).

Methods: Serum levels of IL-6, PTX3, and PCT were measured in 142 enrolled subjects (51 with sepsis, 46 with septic shock, and 45 as controls). Follow-up IL-6 and PTX3 levels were measured in patients with initial septic shock within $24 \mathrm{~h}$ of hospital discharge. Optimal cut-off values were determined for sepsis and septic shock, and prognostic values were evaluated.

Results: Serum IL-6 levels could discriminate sepsis (area under the curve [AUC], 0.83-0.94, $P<0.001$; cut-off value, $52.60 \mathrm{pg} / \mathrm{mL}, 80.4 \%$ sensitivity, $88.9 \%$ specificity) from controls and could distinguish septic shock (AUC, 0.71-0.89; cutoff value, $348.92 \mathrm{pg} / \mathrm{mL}, 76.1 \%$ sensitivity, $78.4 \%$ specificity) from sepsis. Twenty-eight-day mortality was significantly higher in the group with high IL-6 ( $\geq 348.92 \mathrm{pg} / \mathrm{mL})$ than in the group with low IL-6 (<348.92 pg/mL) $(P=0.008)$. IL-6 was an independent risk factor for 28-day mortality among overall patients (hazard ratio, 1.0004; 95\% confidence interval, 1.0003-1.0005; $p=0.024$ ). In septic shock patients, both the initial and follow-up PTX3 levels were consistently significantly higher in patients who died than in those who recovered (initial $p=0.004$; follow-up $P<0.001$ ).
\end{abstract}

Conclusions: The diagnostic and prognostic value of IL- 6 was superior to those of PTX3 and PCT for sepsis and septic shock.

Keywords: Interleukin-6, Pentraxin 3, Procalcitonin, Sepsis, Septic shock, Emergency department

\section{Background}

Sepsis is an important public health issue globally. Despite advances in modern medicine, over 5.3 million people die annually from sepsis, at an estimated overall mortality of $30 \%$ [1-3]. According to the Third International Consensus Definitions for Sepsis

\footnotetext{
* Correspondence: pugae1@hanmail.net

${ }^{2}$ Division of Infectious Diseases, Department of Internal Medicine, Korea

University Ansan Hospital, 123, Jeokgeum-ro, Danwon-gu, Ansan-si, Gyeonggi-do, Republic of Korea

Full list of author information is available at the end of the article
}

and Septic Shock (Sepsis-3), sepsis is defined as lifethreatening organ dysfunction caused by dysregulated host response to infection [1, 2, 4]. Early identification and diagnosis are essential, as prompt and appropriate treatment can improve survival outcomes [5]. Despite pre-existing diagnostic criteria, early diagnosis of sepsis is usually complex due to unknown sources of infection and vague sepsis syndrome definitions [6]. C-reactive protein (CRP) and procalcitonin (PCT) have been widely used to facilitate sepsis diagnosis, but their diagnostic and prognostic values are limited

(c) The Author(s). 2019 Open Access This article is distributed under the terms of the Creative Commons Attribution 4.0 International License (http://creativecommons.org/licenses/by/4.0/), which permits unrestricted use, distribution, and reproduction in any medium, provided you give appropriate credit to the original author(s) and the source, provide a link to the Creative Commons license, and indicate if changes were made. The Creative Commons Public Domain Dedication waiver (http://creativecommons.org/publicdomain/zero/1.0/) applies to the data made available in this article, unless otherwise stated. 
[7-11]. Improved biomarkers are therefore required for the prompt diagnosis of sepsis and prediction of outcomes.

Interleukin-6 (IL-6), a pro-inflammatory cytokine, is synthesized from T-lymphocytes, fibroblasts, endothelial cells, and monocytes [12, 13]. IL-6 serves as an important mediator during the acute phase of response to inflammation in sepsis, and its clinical value has been assessed in patients with various septic conditions in several studies [14-20]. However, the diagnostic and prognostic values of IL- 6 are controversial. A recent study reported that the IL- 6 level is a diagnostic marker of infection as well as a prognostic marker in patients with organ dysfunction [20]. However, a meta-analysis of diagnostic performance showed that IL- 6 offers only moderate success in differentiating sepsis from non-infectious systemic inflammatory response syndrome (SIRS) in adults [12]; the use of IL- 6 was thus recommended as a diagnostic aid to confirm rather than exclude infection in patients with SIRS.

Pentraxin 3 (PTX3), which belongs to the long pentraxin family, is expressed in a variety of cells during various inflammatory processes, including sepsis [21]. PTX3 plays a role in the early phase of inflammation by activating the classical complement pathway and facilitating recognition by macrophages and dendritic cells $[21,22]$. Evidence concerning the clinical value of IL-6 and PTX3 is controversial; however, prior studies have proposed PTX3 as a diagnostic and prognostic marker of sepsis [23-30]. In a systematic review and meta-analysis, PTX3 was identified as a marker of sepsis severity and predictor of mortality [31]. A recent study showed that PTX3 discriminated sepsis and septic shock patients from controls in a medical intensive care unit (ICU) in accordance with the Sepsis-3 definitions [32], suggesting that PTX3 has a diagnostic value comparable to that of IL-6 in sepsis and septic shock.

The present study aimed to investigate both the diagnostic and prognostic values of IL-6, PTX3, and PCT in the emergency department (ED) patients with sepsis and septic shock using the Sepsis-3 definitions.

\section{Methods}

\section{Study design}

This study was a single-center prospective controlled study of sepsis patients who visited the ED of Korea University Ansan Hospital, Korea, which is an 870-bed tertiary care teaching hospital with an annual load of approximately 50,000 patients. The study was conducted from December 13, 2017 to June 5, 2018. The newly developed Intelligent Sepsis
Management System (i-SMS), which employs Sepsis3 definitions, has been used to screen, diagnose, and treat sepsis since September 26, 2017. The system consists of a quick sequential organ-failure assessment (qSOFA) at arrival, determination of the presence or absence of infection, calculation of the sequential organ-failure assessment (SOFA) score, and essential management according to the 2016 Surviving Sepsis Campaign (SSC) guidelines. This study complied with the provisions of the Declaration of Helsinki and was approved by the institutional review board (IRB) of Korea University Medical Center (IRB No. 2017AS0415).

\section{Study population}

During the study period, patients were diagnosed with sepsis if they had an initial positive qSOFA score, the presence of infection, and a SOFA score $\geq$ 2 . Among these patients, we included only adults $(\geq$ 18 years old) who provided written informed consent for the acquisition of biomarker samples. We obtained written informed consent from the legal representatives of patients who were unable to provide consent to participate in the study due to decreased mental capacity. Patients were excluded if they or their legal representatives did not consent to participate or if they presented with cardiac arrest at arrival. Forty-five patients shown to meet initial SIRS criteria but not to have sepsis at a routine check-up (i.e., radiology, blood and urine tests, vital signs, and medical history) in ED were enrolled and served as the control group.

Following data collection, two infectious disease specialists and one emergency attending physician independently reviewed the medical records and clinical data of the enrolled patients to determine sepsis severity and then re-classified enrolled patients into no sepsis, sepsis, and septic shock groups using Sepsis-3 definitions. Light's kappa value for the three raters (i.e., the average kappa value across all rater pairs) was 0.837 .

\section{Definitions}

The Sepsis-3 diagnostic criteria for sepsis include a 2 point or greater increase in SOFA score due to current infection $[1,4]$. The qSOFA score is a prompt bedside method that can identify patients with suspected infection who are at greater risk of a poor outcome outside the ICU [1]. The score ranges from 0 to 3 using three criteria that are each assigned one point: low blood pressure (systolic blood pressure $\leq$ $100 \mathrm{mmHg}$ ), high respiratory rate $(\geq 22$ breaths per min), or altered mentation (Glasgow coma scale score $<15)$. A positive qSOFA score implies the 
presence of 2 or more qSOFA signs near the onset of infection. Although qSOFA criteria are only moderately sensitive regarding sepsis, we adopted positive qSOFA scores as inclusion criteria for the present study. The criteria for septic shock include the requirement of a vasopressor to maintain a mean arterial pressure of $65 \mathrm{mmHg}$ and a serum lactate level greater than $2 \mathrm{mmol} / \mathrm{L}$ despite adequate fluid resuscitation [4]. In accordance with SSC guidelines, serum lactate levels were measured in all patients. Sepsis severity was assessed by both the SOFA score and an acute physiology and chronic health evaluation II (APACHE II) score [33, 34].

\section{Sampling for biomarkers and clinical data collection}

All blood samples for initial IL-6, PTX3, and PCT measurements were obtained within $6 \mathrm{~h}$ of the clinical diagnosis of sepsis or septic shock. Whole blood was collected in serum-separating tubes. Serum was separated, and aliquots were frozen at $-80^{\circ} \mathrm{C}$ until analysis. Serum biomarker levels were measured in duplicate in samples kept on ice prior to measurement. Serum IL-6 and PTX3 levels were measured using commercially available enzyme-linked immunosorbent assays (ELISA, R\&D Systems, Minneapolis, MN, USA). IL-6 inter- and intra-assay variabilities were $4.5 \pm 1.7 \%$ and $2.6 \pm 1.4 \%$, respectively, and those of PTX3 were $5.1 \pm 1.1 \%$ and $3.9 \pm 0.4 \%$, respectively. PCT levels in serum were measured using reagents from Thermo Fisher Scientific (Thermo Fisher Scientific Clinical Diagnostics, BRAHMS GmbH, Hennigsdorf, Germany). CRP levels were measured by an immunoturbidimetric assay using a Modular P800 automatic analyzer (Roche Diagnostics GmbH, Mannheim, Germany).

Vital signs (blood pressure, heart rate, respiratory rate, and body temperature), routine laboratory test results (creatinine, bilirubin, platelet count, CRP, PCT, hemoglobin, hematocrit, sodium, potassium, urea, lactate, white blood cell count, and blood culture), biomarker measurement (PTX3 and IL-6), blood gas analysis $\left(\mathrm{pH}, \mathrm{PaO}_{2}, \mathrm{PaCO}_{2}\right.$, bicarbonate, and base excess), Glasgow coma scale (GCS) scores, and personal information (age, sex, body weight, and prior medical history) were collected and documented.

\section{Statistical analysis}

We performed statistical analysis using PASW Statistics for Windows version 18.0 (SPSS Inc., Chicago, IL, USA) and Medcalc Statistical Software version 18.5 (Medcalc Software bvba, Ostend, Belgium). Comparisons between two groups were performed using Student's $t$-test. For more than two groups, quantitative variables were compared using one-way analysis of variance or the Kruskal-Wallis test according to the distribution normality. For quantitative variables, Student's $t$-test or the Mann-Whitney $U$-test were applied depending on data distribution. Qualitative variables were analyzed using a $2 \times 2$ contingency table and chi-squared test or Fisher's exact test as appropriate. Quantitative variables are presented as the mean \pm standard error of the mean or as median and interquartile ranges (IQRs), according to data distribution. The accuracy of IL-6, PTX3, and PCT in differentiating sepsis and septic shock patients from controls was assessed using receiver operating characteristic curves. In this method, a perfect biomarker has $100 \%$ sensitivity, shows no false positives $(100 \%$ specificity), and produces an area under the curve (AUC) of 1.0, while a biomarker with no diagnostic value has an AUC of 0.5. We used Youden's index with the highest sum of sensitivity and specificity to determine the optimal cut-off value for differentiation. Correlations between the levels of IL-6, PTX3, PCT, CRP, and lactate; SOFA score; and APACHE II score were analyzed using Spearman's rank test. KaplanMeier curve analysis and a log-rank test were performed to assess the cumulative survival rate and compare the survival curves of groups with lower IL6 or PTX3 levels with those of the higher-level groups. Univariate and multivariate Cox regression analyses were performed to evaluate the risk factors for 28-day mortality.

\section{Results}

\section{Patients' demographics}

A flow chart of the study population is presented in Fig. 1. Of the 192 patients clinically diagnosed with sepsis and septic shock, 79 were excluded either due to refusal of study participation $(n=77)$ or inadequate samples $(n=2)$. Therefore, 113 blood samples were initially eligible for biomarker measurements (64 for sepsis and 49 for septic shock). After retrospective re-evaluation, 16 subjects in the initial sepsis group were excluded because they did not meet the criteria for sepsis (i.e., no evidence of infection). The final diagnoses of these 16 subjects were congestive heart failure $(n=3)$, pulmonary thromboembolism $(n=2)$, acute kidney injury $(\mathrm{n}=2)$, a hyperosmolar hyperglycemic state $(n=2)$, hepatorenal syndrome $(n=2)$, chronic obstructive pulmonary disease $(n=2)$, and others $(n=$ 3). After retrospective re-evaluation, three subjects in the initial septic shock group were recategorized to the sepsis group because they did not meet the criteria for septic shock. The final patient populations were as follows: 51 with sepsis, 46 with septic shock, and 45 as controls. Overall, 142 subjects 


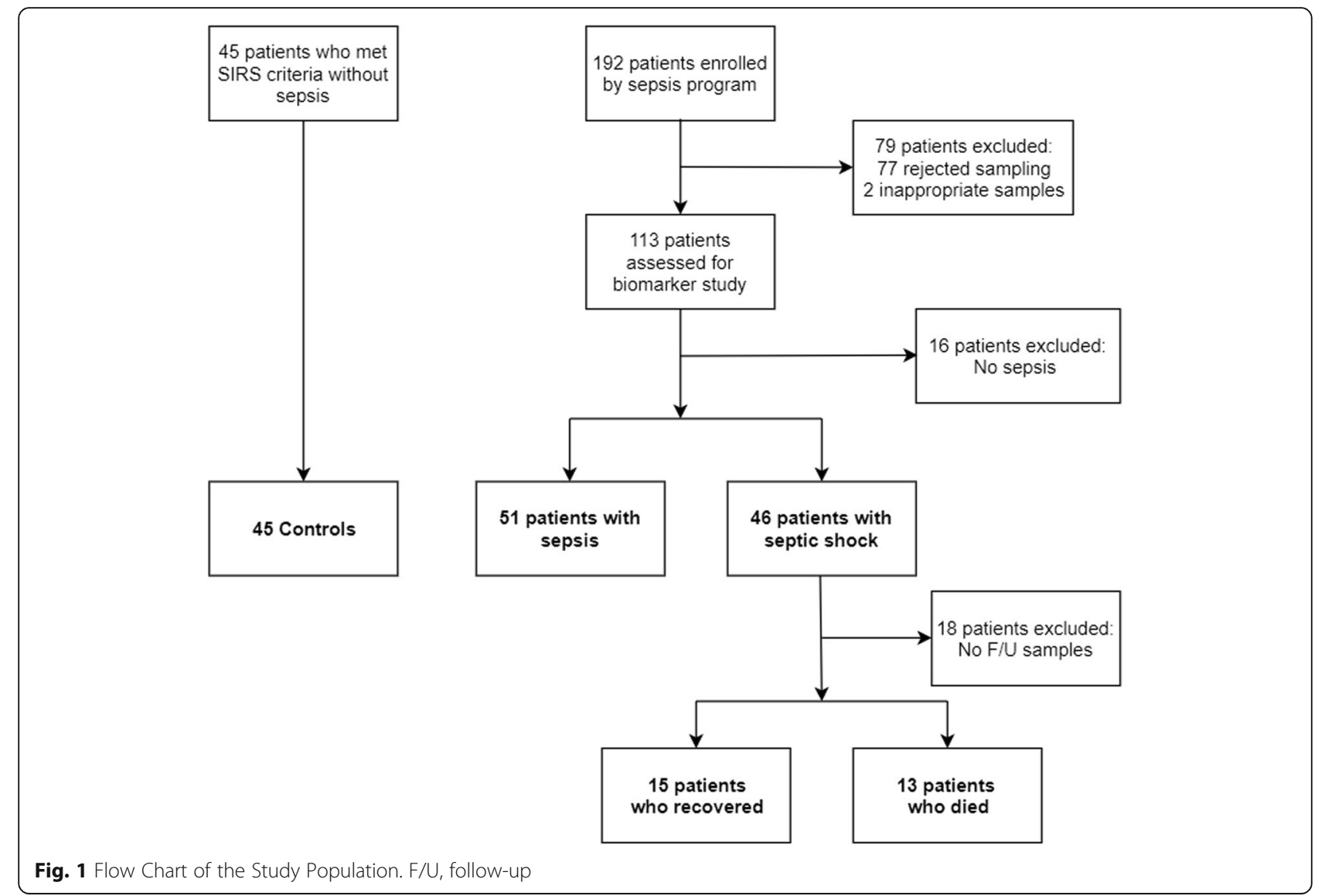

were enrolled in the present study. From the 46 septic shock patients admitted to our institution, follow-up samples were obtained from 28 patients within 24h of discharge to measure IL-6 and PTX3, 15 of whom recovered, and 13 died. The remaining 18 patients were excluded due to refusal to provide a blood sample, transfer to other institutions, sudden death, or undetermined outcomes (still on admission). Baseline characteristics of the study population are shown in Table 1. The most common infection sites were the respiratory $(64.9 \%)$ and genitourinary systems (33.0\%).

\section{Correlations with other biomarkers and severity score}

IL-6 levels showed positive correlations with PTX3 (rho $=0.802, P<0.001)$, lactate (rho $=0.798, P<0.001$ ), PCT $\quad($ rho $=0.752, \quad P<0.001), \quad$ CRP $\quad($ rho $=0.476$, $\mathrm{P}<0.001)$, SOFA score $(\mathrm{rho}=0.421, P<0.001)$, and APACHE II score (rho $=0.407, P<0.001$ ) by Spearman's rank analysis.

\section{Diagnostic value of biomarkers}

The median IL-6 values (IQR) in the control, sepsis, and septic shock groups were 23.6 (11.2-43.5), 89.9
(45.2-272.6), and $1378.6(256.4-11,062.1) \mathrm{pg} / \mathrm{mL}$, respectively (Fig. 2); those for PTX3 were 4 (2-13), $25(10-51)$, and $74(26-147) \mathrm{ng} / \mathrm{mL}$, respectively; those for PCT were $0.2(0.1-0.23), 0.3$ (0.1-1.1), and $3.4(1.3-20.1) \mathrm{ng} / \mathrm{mL}$, respectively; and those for lactate were $0.9(0.5-1.5), 1.9(0.9-2.9)$, and 5.5 (3.0-8.1) $\mathrm{mmol} / \mathrm{L}$, respectively. The three groups showed significant differences in the levels of these four biomarkers, as determined by Kruskal-Wallis and post hoc tests $(P<0.001)$. The median CRP values (IQR) in the control, sepsis, and septic shock groups were $3.6(2.0-5.2), 9.9(4.9-20.2)$, and 10.5 (7.3-21.0) $\mathrm{mg} / \mathrm{dL}$, respectively. There were significant differences between the control and other groups $(P<0.001)$; however, no significant difference was found between the sepsis and septic shock groups $(P=0.45)$.

The AUC of IL-6 to discriminate sepsis from the control group was 0.89 (95\% confidence interval [CI], 0.97-1.00; $P<0.001$ ), 0.84 for PTX3 (95\% CI, 0.950.99; $P<0.001), 0.80$ for PCT (95\% CI, 0.86-0.96; $\mathrm{P}<$ 0.001 ), and 0.77 for CRP (95\% CI, 0.71-0.91; $P<$ 0.001) (Table 2 and Fig. 3). The optimal cut-off value to discriminate sepsis from controls was $52.60 \mathrm{pg} / \mathrm{mL}$ 
Table 1 Baseline Characteristics of the Study Population

\begin{tabular}{|c|c|c|c|c|}
\hline Variable & $\begin{array}{l}\text { Total patients } \\
(n=97)\end{array}$ & $\begin{array}{l}\text { Sepsis } \\
(n=51)\end{array}$ & $\begin{array}{l}\text { Septic shock } \\
(n=46)\end{array}$ & $\begin{array}{l}\text { Controls } \\
(n=45)\end{array}$ \\
\hline Age, median (range) & $\begin{array}{l}75 \\
(42-98)\end{array}$ & $\begin{array}{l}76(42- \\
98)\end{array}$ & $74(42-96)$ & $\begin{array}{l}68 \\
(37-81)\end{array}$ \\
\hline \multicolumn{5}{|l|}{ Sex, n (\%) } \\
\hline Male & $54(56)$ & $28(55)$ & $26(57)$ & $25(56)$ \\
\hline Female & $43(44)$ & $23(45)$ & $20(43)$ & $20(44)$ \\
\hline \multicolumn{5}{|l|}{ Infection site, $n(\%)$} \\
\hline Respiratory & $63(64.9)$ & $33(64.7)$ & $30(65.2)$ & - \\
\hline Genitourinary & $32(33.0)$ & $19(37.3)$ & $13(28.3)$ & - \\
\hline Cardiovascular & $3(3.1)$ & $0(0.0)$ & $3(6.5)$ & - \\
\hline Gastrointestinal & $2(2.1)$ & $0(0.0)$ & $2(4.3)$ & - \\
\hline Musculoskeletal & $2(2.1)$ & $1(2.0)$ & $1(2.2)$ & - \\
\hline Central nervous & $1(1.0)$ & $0(0.0)$ & $1(2.2)$ & - \\
\hline Hepatobiliary & $1(1.0)$ & $0(0.0)$ & $1(2.2)$ & - \\
\hline $\begin{array}{l}\text { Skin and soft } \\
\text { tissue }\end{array}$ & $1(1.0)$ & $1(2.0)$ & $0(0.0)$ & - \\
\hline Unknown & $5(5.2)$ & $2(3.9)$ & $3(6.5)$ & - \\
\hline \multicolumn{5}{|l|}{ Underlying disease } \\
\hline $\begin{array}{l}\text { Coronary artery } \\
\text { disease }\end{array}$ & $11(11.3)$ & $5(9.8)$ & $6(13.0)$ & - \\
\hline Malignancy & $10(10.3)$ & $4(7.8)$ & $6(13.0)$ & - \\
\hline Rheumatic disease & $4(4.1)$ & $2(3.9)$ & $2(4.3)$ & - \\
\hline $\begin{array}{l}\text { SOFA score, median } \\
\text { (IQR) }\end{array}$ & $8(4-11)$ & $6(3-9)$ & $10(6-13)$ & - \\
\hline $\begin{array}{l}\text { APACHE II score, } \\
\text { median (IQR) }\end{array}$ & $21(13-30)$ & $\begin{array}{l}18(10- \\
27)\end{array}$ & $25(16-35)$ & - \\
\hline \multicolumn{5}{|l|}{$\begin{array}{l}\text { Laboratory value, } \\
\text { median (IQR) or } \\
\text { mean } \pm \text { SEM }\end{array}$} \\
\hline $\begin{array}{l}\text { Procalcitonin } \\
\text { (ng/mL) }\end{array}$ & $1.6(0.5-10.7)$ & $\begin{array}{l}0.3 \\
(0.2-1.2)\end{array}$ & $\begin{array}{l}3.4 \\
(1.6-20.3)\end{array}$ & \\
\hline CRP (mg/dL) & $10(6-20)$ & $\begin{array}{l}10 \\
(5-20)\end{array}$ & $11(7-21)$ & \\
\hline $\begin{array}{l}\text { Lactate } \\
(\mathrm{mmol} / \mathrm{L})\end{array}$ & $3.6(2.6-4.6)$ & $\begin{array}{l}1.9 \\
(1.1-2.8)\end{array}$ & $\begin{array}{l}5.5 \\
(3.6-7.5)\end{array}$ & \\
\hline $\begin{array}{l}\text { Creatinine } \\
(\mathrm{mg} / \mathrm{dL})\end{array}$ & $2.5 \pm 0.2$ & $2.1 \pm 0.2$ & $2.9 \pm 0.2$ & \\
\hline Bilirubin (mg/dL) & $2.2 \pm 0.4$ & $1.7 \pm 0.3$ & $2.8 \pm 0.5$ & \\
\hline $\begin{array}{l}\text { Platelet } \\
(\times 1000 / \mu \mathrm{L})\end{array}$ & $203 \pm 12.4$ & $\begin{array}{l}251 \pm \\
14.3\end{array}$ & $153 \pm 10.6$ & \\
\hline $\begin{array}{l}\text { Positive blood } \\
\text { cultures, n (\%) }\end{array}$ & $75(77.3)$ & 35 (68.6) & $40(87.0)$ & - \\
\hline $\begin{array}{l}\text { ICU days, median } \\
\text { (IQR) }\end{array}$ & $9(5-14)$ & $8(4-11)$ & $11(7-16)$ & - \\
\hline $\begin{array}{l}\text { Length of stay, } \\
\text { median (IQR) }\end{array}$ & $13(8-18)$ & $11(7-16)$ & 15 (9-19) & - \\
\hline
\end{tabular}

SOFA sequential organ-failure assessment, IQR interquartile range, APACHE acute physiology and chronic health evaluation, CRP C-reactive protein, SEM standard error of the mean, ICU intensive care unit for IL-6 (sensitivity, 97.0\%; specificity, 97.2\%; $P<$ 0.001 ) (Table 3) and $15.10 \mathrm{ng} / \mathrm{mL}$ for PTX3 (sensitivity, 92.6\%; specificity, 97.4\%; $P<0.001)$.

The AUC to discriminate septic shock was 0.80 for IL6 (95\% CI, 0.71-0.89; $P<0.001$ ), 0.70 for PTX3 (95\% CI, $0.60-0.81 ; \mathrm{P}<0.001), 0.73$ for PCT (95\% CI, 0.63-0.83; $P<0.001$ ), and 0.53 for CRP (95\% CI, $0.42-0.65 ; P=$ 0.603 ) (Table 2 and Fig. 3). The optimal cut-off value to discriminate septic shock was $348.92 \mathrm{pg} / \mathrm{mL}$ for IL-6 (91.8\% sensitivity, $63.2 \%$ specificity, $\mathrm{P}<0.001$ ) (Table 3 ) and $58.28 \mathrm{ng} / \mathrm{mL}$ for PTX3 (93.2\% sensitivity, $60.7 \%$ specificity, $\mathrm{P}<0.001$ ).

\section{Prognostic value of biomarkers}

Univariate and multivariate Cox regression analysis results for the risk factors of 28-day mortality are shown in Table 4. The univariate analysis determined that the significant risk factors for 28-day mortality were IL-6, PTX3, lactate, SOFA and APACHE II scores, and septic shock. The significant risk factors determined by multivariate analysis were IL-6 (hazard ratio [HR], 1.0004; 95\% CI, $1.0003-1.0005 ; P=0.024)$, SOFA score (HR, 1.128; 95\% CI, $1.030-1.211 ; P=0.011)$, and lactate (HR, 1.135; 95\% CI, 1.033-1.247; $P=0.009$ ).

Kaplan-Meier curve analyses and log-rank tests were performed to assess cumulative survival rates and compare 28-day survival curves between the high IL-6 ( $\geq$ $348.9 \mathrm{pg} / \mathrm{mL})$ and low IL-6 $(<348.9 \mathrm{pg} / \mathrm{mL})$ groups. The optimal cut-off value of IL-6 to predict septic shock in the present study was $348.9 \mathrm{pg} / \mathrm{mL}$. The survival curve of the high IL- 6 group significantly differed from that of the low IL-6 group in log-rank tests $(P=0.008)$ (Fig. 4). Kaplan-Meier curve analyses and log-rank tests were also performed to assess cumulative survival rates and compare the 28-day survival curves between the high PTX3 ( $\geq 58.28 \mathrm{ng} / \mathrm{mL})$ and low PTX3 $(<58.28 \mathrm{ng} / \mathrm{mL})$ groups. The optimal cut-off value of PTX3 to predict septic shock was $58.28 \mathrm{ng} / \mathrm{mL}$. The survival curve of the high PTX3 group significantly differed from that of the low PTX3 group in log-rank tests $(P=0.043)$ (Fig. 4).

Among the patients with septic shock at presentation, initial IL-6 levels within $6 \mathrm{~h}$ of clinical diagnosis in the recovered survivors $(n=15)$ and non-survivors $(n=13)$ were 444.3 (261.2-5893.5) and 7609.5 (4526.0-12,208.4) $\mathrm{pg} / \mathrm{mL}$, respectively $(P=0.05)$, and follow-up IL-6 levels within $24 \mathrm{~h}$ of discharge were $21.5(10.2-51.7)$ and $9976.5(4651.2-71,048.3) \mathrm{pg} / \mathrm{mL}$, respectively $(P<0.001)$. Among the same patients, initial PTX3 levels within $6 \mathrm{~h}$ of clinical diagnosis were $29(10-75)$ and $126(70-147)$ $\mathrm{ng} / \mathrm{mL}$, respectively $(P=0.007)$ (Fig. 5$)$, and follow-up PTX3 levels within $24 \mathrm{~h}$ of discharge were $4(2-7)$ and $188(101-376) \mathrm{ng} / \mathrm{mL}$, respectively $(P<0.001$. Error bars represent the variability of data in Fig. 5. Both IL-6 and PTX3 levels significantly decreased in the recovered 


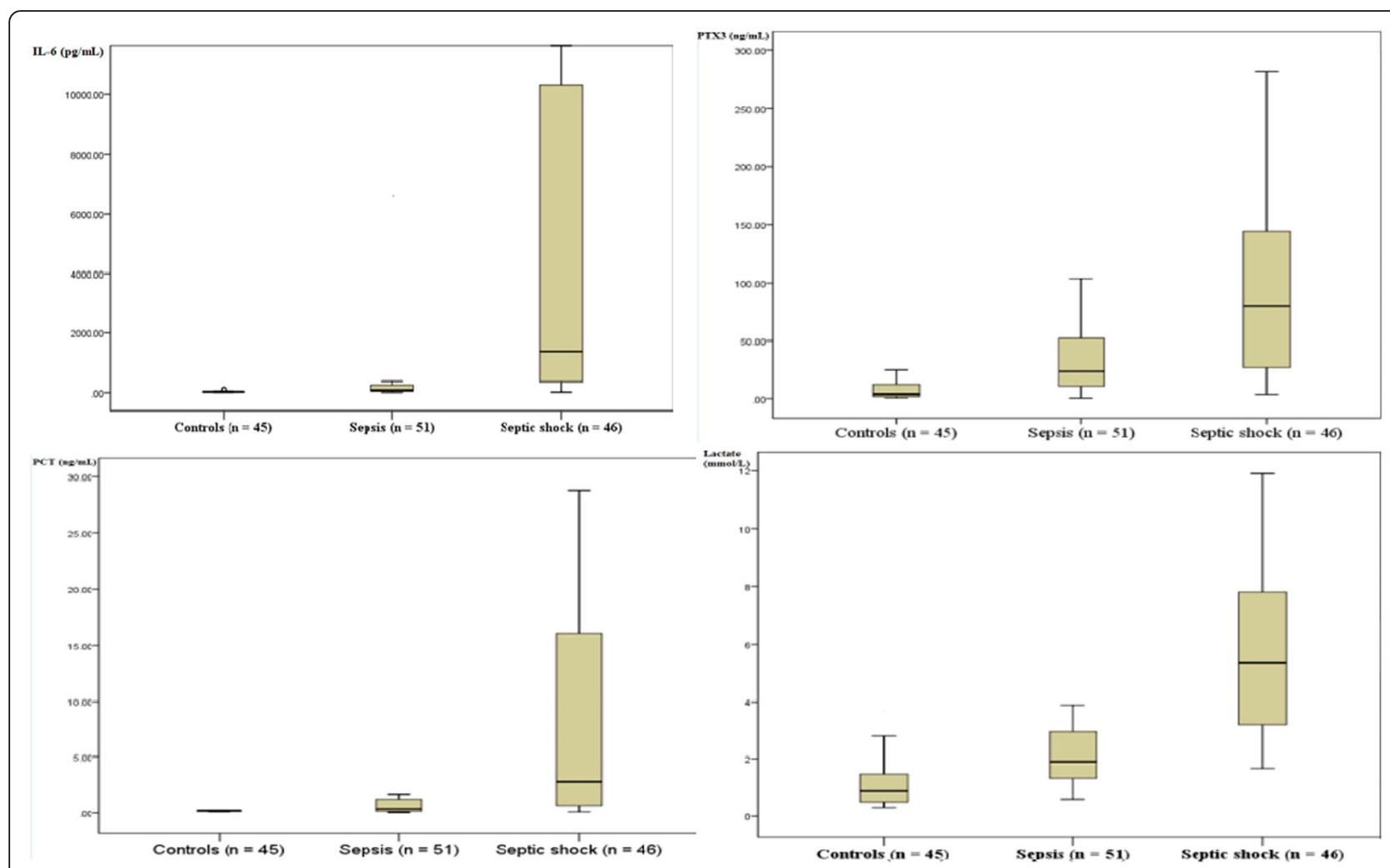

Fig. 2 Interleukin-6, pentraxin 3, procalcitonin, and lactate levels in sepsis and septic shock patients. Patients were diagnosed in the emergency department according to Sepsis-3 definitions. CRP, C-reactive protein

survivors $(\mathrm{P}<0.001$ and $\mathrm{P}<0.001$, respectively); however, both levels remained high and even significantly increased in the non-survivors $(P=0.03$ and $P=0.009$, respectively).

\section{Combination of IL- 6 and PTX3 to predict severity and mortality}

Multivariate logistic regression was performed to model the ability of the biomarker combination (IL-6 and PTX3) to discriminate septic shock patients from sepsis and to predict 28-day mortality among the overall patients. Using the logistic regression equation, the log of probability was converted to the probability of septic shock and 28-day mortality. The AUC values of combined marker score (probability of septic shock) and each biomarker for the discrimination of septic shock are shown in Table 5. The AUC values of combined marker score (probability of 28-day mortality) and each biomarker for the prediction of 28-day mortality are shown in Table 6.

\section{Discussion}

In the present study, we evaluated the diagnostic and prognostic values of IL-6, PTX3, PCT, CRP, and lactate in patients with sepsis and septic shock diagnosed using Sepsis-3 definitions. The results showed that serum IL-6 and PTX3 levels could identify the severity of sepsis (sepsis, septic shock, and controls) with optimal cut-off values. IL-6 had superior diagnostic and prognostic value compared with PTX3, PCT, and CRP. Furthermore, IL-6

Table 2 Comparisons of the Discriminating Capacities between Biomarkers Presented as Areas Under the Curve (95\% Cl)

\begin{tabular}{llllll}
\hline Severity & Interleukin-6 & Pentraxin 3 & Procalcitonin & Lactate & C-reactive protein \\
\hline Sepsis $(n=97)$ & 0.89 & 0.84 & 0.80 & 0.88 & 0.77 \\
& $(0.83-0.94)$ & $(0.78-0.91)$ & $(0.73-0.87)$ & $(0.82-0.94)$ & $(0.70-0.85)$ \\
Septic shock $(n=46)$ & $P<0.001$ & $P<0.001$ & $P<0.001$ & $P<0.001$ & $P<0.001$ \\
& 0.80 & 0.70 & 0.73 & 0.85 & 0.53 \\
& $(0.71-0.89)$ & $(0.60-0.81)$ & $(0.63-0.83)$ & $(0.77-0.93)$ & $(0.42-0.65)$ \\
& $P<0.001$ & $P=0.001$ & $P<0.001$ & $P<0.001$ & $P=0.603$ \\
\hline
\end{tabular}




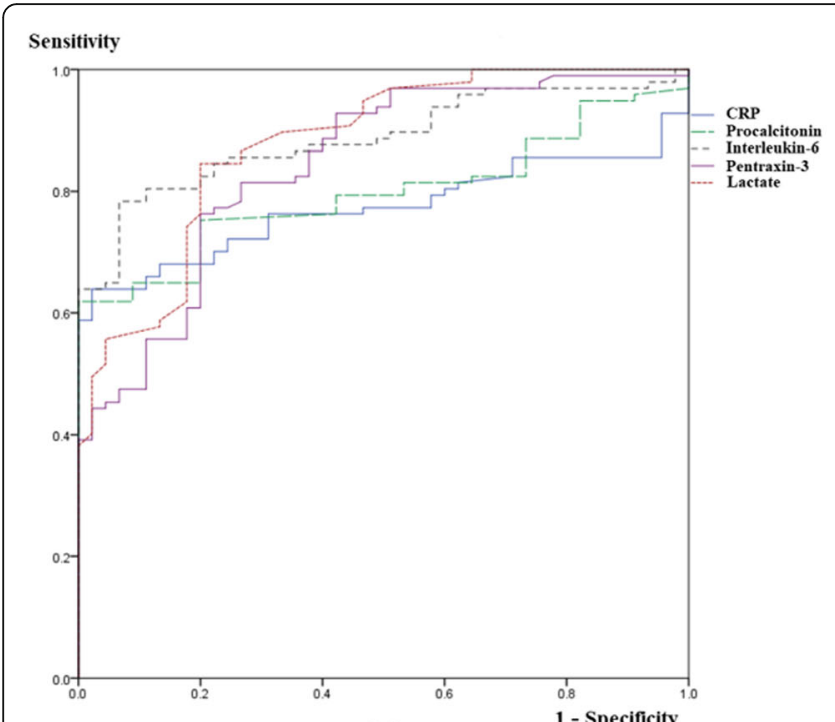

(a)

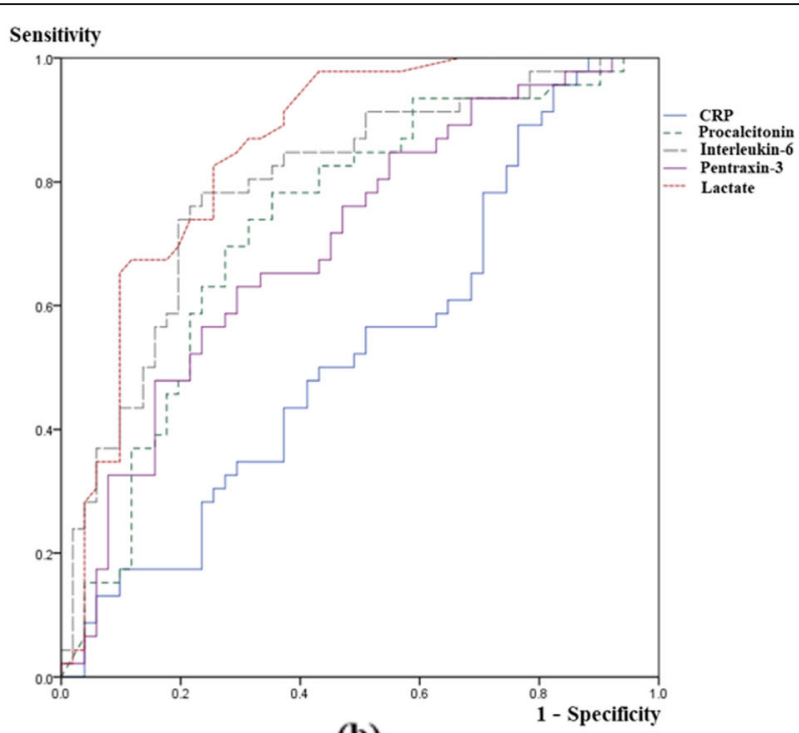

(b)

Fig. 3 Receiver operating characteristic curves for distinguishing sepsis or septic shock. Sepsis (a) and septic shock (b) are variously discriminated by interleukin-6, pentraxin 3, lactate, and procalcitonin levels measured in the emergency department

was an independent risk factor for 28-day mortality in patients with sepsis and septic shock.

Several previous studies have presented conflicting results regarding the diagnostic value of biomarkers such as IL-6, PTX3, PCT, presepsin, and CRP $[12,16,18-20$, $32,35,36]$. Reports in which IL-6 was a better diagnostic marker for sepsis than PCT, presepsin, and CRP [20, 35] are consistent with our study. However, some studies have demonstrated that the diagnostic value of PCT was superior to that of IL-6 $[16,19,36]$, and others have suggested that the diagnostic value of IL-6 was nearly equal to that of PCT or PTX3 in septic patients [12, 32]. Previous studies that evaluated the clinical value of several biomarkers including IL-6 are shown in Table 7.

A recent study reported that serum IL-6 levels had the highest diagnostic value for infection in patients with

Table 3 Diagnostic Value of Interleukin-6 and Pentraxin 3 for Patients with Sepsis and Septic Shock

\begin{tabular}{|c|c|c|c|c|c|c|}
\hline Biomarker & Severity & $\begin{array}{l}\text { AUC } \\
(95 \% \mathrm{Cl})\end{array}$ & $\begin{array}{l}\text { Cut-off } \\
\text { value }\end{array}$ & $\begin{array}{l}\text { Sensitivity } \\
(\%)\end{array}$ & $\begin{array}{l}\text { Specificity } \\
(\%)\end{array}$ & $\begin{array}{l}P \\
\text { value }\end{array}$ \\
\hline IL-6 & Sepsis & $\begin{array}{l}0.89 \\
(0.83-0.94)\end{array}$ & 52.60 & 80.4 & 88.9 & $\begin{array}{l}< \\
0.001\end{array}$ \\
\hline$(\mathrm{pg} / \mathrm{mL})$ & $\begin{array}{l}\text { Septic } \\
\text { shock }\end{array}$ & $\begin{array}{l}0.80 \\
(0.71-0.89)\end{array}$ & 348.92 & 76.1 & 78.4 & $\begin{array}{l}< \\
0.001\end{array}$ \\
\hline PTX3 & Sepsis & $\begin{array}{l}0.84 \\
(0.78-0.91)\end{array}$ & 15.10 & 76.3 & 80.0 & $\begin{array}{l}< \\
0.001\end{array}$ \\
\hline$(\mathrm{ng} / \mathrm{mL})$ & $\begin{array}{l}\text { Septic } \\
\text { shock }\end{array}$ & $\begin{array}{l}0.70 \\
(0.60-0.81)\end{array}$ & 58.28 & 56.5 & 76.5 & 0.001 \\
\hline
\end{tabular}

AUC area under the curve, Cl confidence interval, IL-6 interleukin-6, PTX3 pentraxin 3 organ dysfunction compared with PCT and CRP levels [20]. Another study reported that serum IL-6 levels had the highest diagnostic value for septic shock compared with PCT, presepsin, and CRP [35]. These results are in agreement with our result that IL-6 was superior to

Table 4 Univariate and Multivariate Cox Proportional Models of Risk Factors for 28-day Mortality

\begin{tabular}{|c|c|c|c|c|}
\hline Variable & HR $(95 \%$ Cl) & $P$ value & $\begin{array}{l}\text { Adjusted } \\
\text { HR (95\% Cl) }\end{array}$ & $P$ value \\
\hline Age & $\begin{array}{l}1.023 \\
(0.994-1.052)\end{array}$ & 0.120 & & \\
\hline Male sex & $\begin{array}{l}1.029 \\
(0.535-1.978)\end{array}$ & 0.932 & & \\
\hline SOFA score & $\begin{array}{l}1.206 \\
(1.076-1.353)\end{array}$ & 0.001 & $\begin{array}{l}1.128 \\
(1.030-1.211)\end{array}$ & 0.011 \\
\hline APACHE II score & $\begin{array}{l}1.198 \\
(1.068-1.346)\end{array}$ & 0.001 & $\begin{array}{l}1.031 \\
(0.898-1.187)\end{array}$ & 0.231 \\
\hline Pentraxin 3 & $\begin{array}{l}1.005 \\
(1.001-1.009)\end{array}$ & 0.031 & $\begin{array}{l}1.003 \\
(0.998-1.008)\end{array}$ & 0.095 \\
\hline Interleukin 6 & $\begin{array}{l}1.001 \\
(1.000-1.002)\end{array}$ & 0.017 & $\begin{array}{l}1.001 \\
(1.000-1.002)\end{array}$ & 0.024 \\
\hline Procalcitonin & $\begin{array}{l}0.995 \\
(0.981-1.009)\end{array}$ & 0.481 & & \\
\hline Lactate & $\begin{array}{l}1.167 \\
(1.068-1.275)\end{array}$ & 0.001 & $\begin{array}{l}1.135 \\
(1.033-1.247)\end{array}$ & 0.009 \\
\hline CRP & $\begin{array}{l}1.011 \\
(0.978-1.045)\end{array}$ & 0.525 & & \\
\hline Septic shock & $\begin{array}{l}2.657 \\
(1.327-5.317)\end{array}$ & 0.004 & $\begin{array}{l}1.249 \\
(0.472-3.302)\end{array}$ & 0.240 \\
\hline
\end{tabular}

HR hazard ratio, $\mathrm{Cl}$ confidence interval, GCS Glasgow coma scale, SOFA sequential organ-failure assessment, APACHE acute physiology and chronic health evaluation, $C R P$ C-reactive protein 


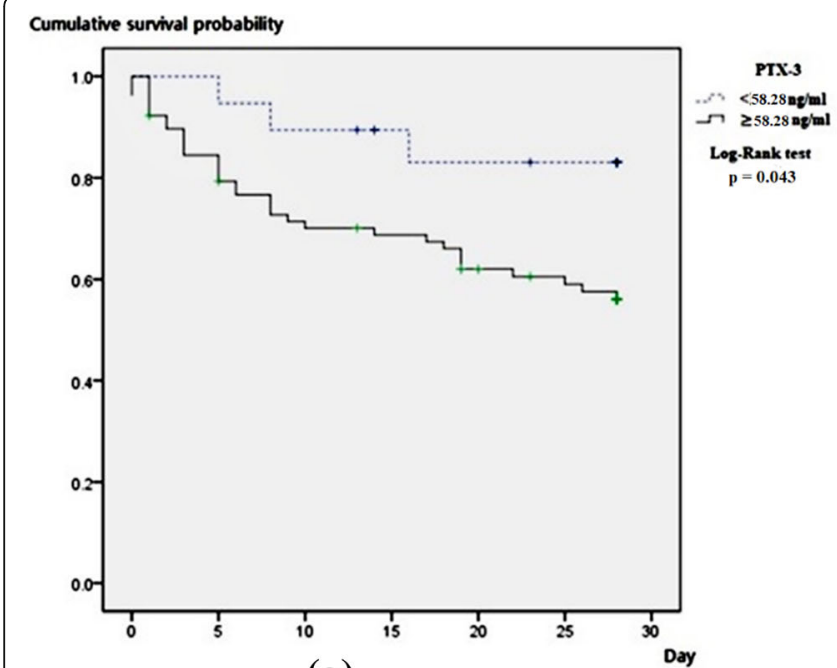

(a)

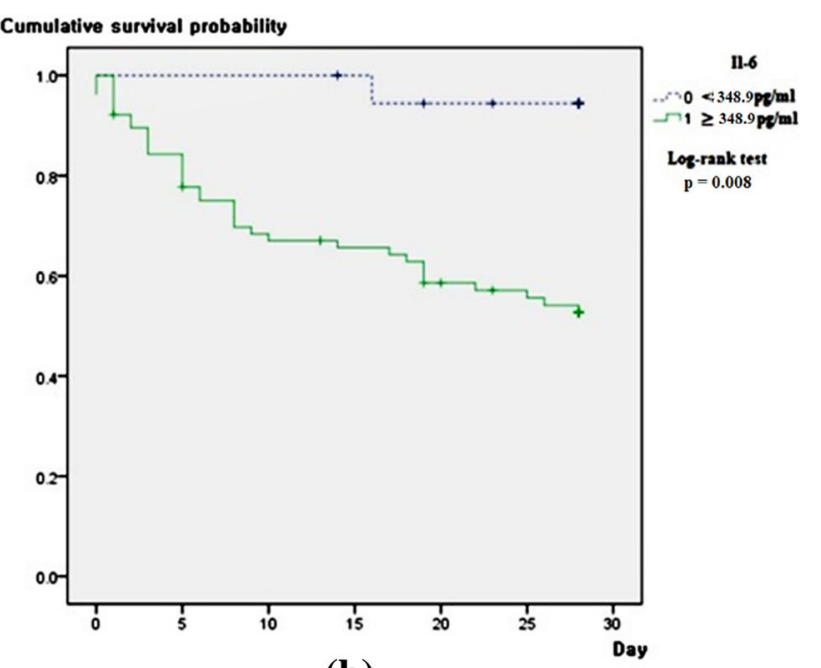

(b)

Fig. 4 Kaplan-Meier curve of 28-day mortality in patients with sepsis and septic shock. The curve is stratified by the optimal cut-off value of pentraxin 3 (a) and interleukin-6 (b) to predict septic shock (28-day mortality by pentraxin 3: 14.6\% vs. 45.9\%; 28-day mortality by interleukin-6: $5.1 \%$ vs. $49.1 \%)$

PTX3, PCT, and CRP in diagnostic value for sepsis and septic shock. In contrast to our study, some have reported that PCT is superior to IL-6 for diagnosing severe sepsis and septic shock [16, 19, 36, 37]. We postulate that this discrepancy was caused by not only different settings (ED versus ICU), but also different severity levels or definitions of sepsis among the study populations (Sepsis-2 versus Sepsis-3). According to Hamed et al., IL-6 has diagnostic value that is comparable, but not superior, to PTX3 and PCT in patients with sepsis and septic shock diagnosed using Sepsis- 3 definitions [32]. A recent meta-analysis reported that IL-6 and PCT had similar diagnostic values that were higher than that of CRP [12].

In line with the current study, several studies showed that, among various inflammatory biomarkers, IL-6 is

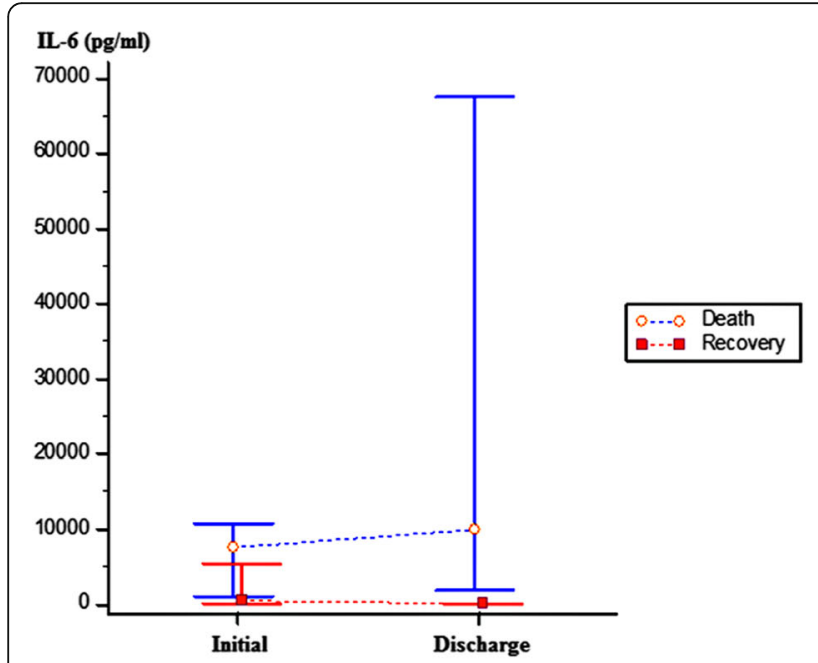

(a)

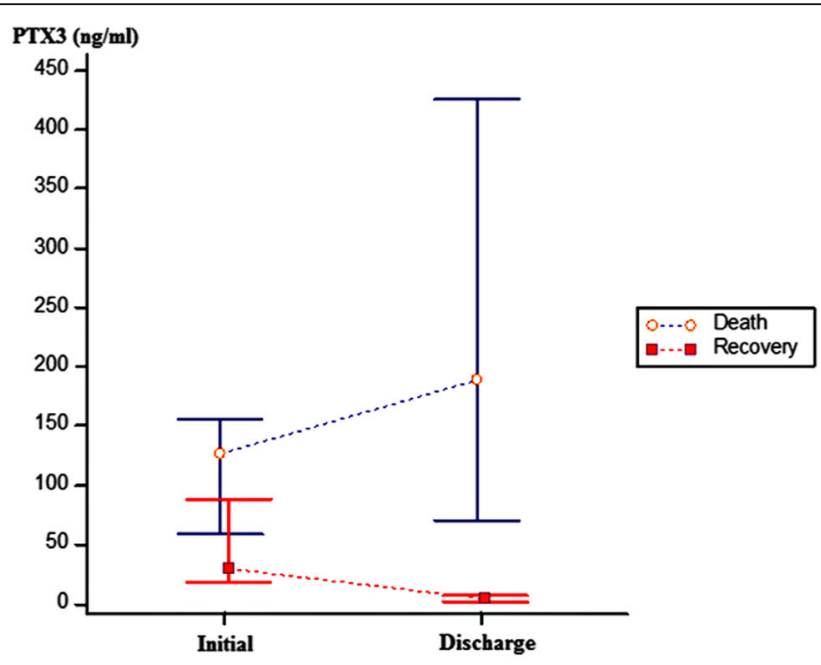

(b)

Fig. 5 Error bars of initial and follow-up levels of interleukin-6 and pentraxin 3. Error bars are shown for the levels of interleukin-6 (a) and pentraxin 3 (b) in septic shock patients who died or recovered during admission. Initial and follow-up levels were taken within $6 \mathrm{~h}$ of clinical diagnosis and $24 \mathrm{~h}$ of discharge, respectively 
Table 5 Discriminating performance of the combined marker (IL-6 + PTX3), IL-6, and PTX3 for septic shock

\begin{tabular}{|c|c|c|c|c|c|}
\hline Biomarkers & $\begin{array}{l}\text { AUC } \\
(95 \% \mathrm{Cl})\end{array}$ & $p$ & Cut-off & $\begin{array}{l}\text { Sensitivity } \\
(\%)\end{array}$ & $\begin{array}{l}\text { Specificity } \\
(\%)\end{array}$ \\
\hline $\begin{array}{l}\text { IL-6+ } \\
\text { PTX3 }\end{array}$ & $\begin{array}{l}0.806 \\
(0.719-0.894)\end{array}$ & $\begin{array}{l}< \\
0.001\end{array}$ & $\begin{array}{l}52.0 \\
\text { (score) }\end{array}$ & 82.7 & 71.1 \\
\hline IL-6 & $\begin{array}{l}0.795 \\
(0.702-0.883)\end{array}$ & $\begin{array}{l}< \\
0.001\end{array}$ & $\begin{array}{l}348.92 \\
(\mathrm{pg} / \mathrm{mL})\end{array}$ & 76.1 & 78.4 \\
\hline PTX3 & $\begin{array}{l}0.703 \\
(0.603-0.812)\end{array}$ & 0.001 & $\begin{array}{l}58.28 \\
(\mathrm{ng} / \mathrm{mL})\end{array}$ & 56.5 & 76.5 \\
\hline
\end{tabular}

AUC area under the curve, $C l$ confidence interval, IL-6 interleukin-6, PTX3 pentraxin 3

the most valuable for predicting outcomes [18-20, 36]. These studies demonstrated that IL- 6 is an independent predictor of in-hospital mortality. Another study reported that IL-6 exhibits superior kinetics when monitoring the effectiveness of antibiotic treatments [19] and suggested that clinicians can use IL- 6 as a prognostic marker in sepsis. In the present study, IL-6 levels in the initial blood samples obtained from patients with septic shock significantly decreased in the recovery group but increased among the death group, which suggests that IL-6 levels can be used to monitor the effectiveness of treatment for septic shock. Another study showed that IL-6 levels in septic shock did not fall near normal levels within the first $24 \mathrm{~h}$ of treatment and instead remained high until clinical recovery [15]. In the present study, because the follow-up IL-6 levels were measured within 24 $\mathrm{h}$ of discharge (recovery or death), direct comparison with the previous study may be difficult. Nevertheless, we speculate that combining follow-up IL-6 levels with initial levels could be of additional value for predicting mortality in patients with septic shock.

PTX3 was proposed as a diagnostic and prognostic marker for sepsis $[10,23-28,30,31,35]$. In a recent systemic review and meta-analysis, PTX3 was reported as a marker of sepsis severity and predictor of mortality [31]; however, these results were drawn from sepsis diagnoses determined by the past Sepsis- 2 definitions. In a recent study, PTX3 distinguished sepsis and septic shock from controls, which corresponds to uniform cut-off levels in

Table 6 Predictive performance of the combined marker (IL-6+ PTX3), IL-6, and PTX3 for 30-day mortality

\begin{tabular}{|c|c|c|c|c|c|}
\hline Biomarkers & $\begin{array}{l}\text { AUC }(95 \% \\
C \mathrm{Cl})\end{array}$ & $p$ & Cut-off & $\begin{array}{l}\text { Sensitivity } \\
(\%)\end{array}$ & $\begin{array}{l}\text { Specificity } \\
(\%)\end{array}$ \\
\hline $\begin{array}{l}\text { IL-6+ } \\
\text { PTX3 }\end{array}$ & 0.637 & 0.025 & $\begin{array}{l}33.1 \\
\text { (score) }\end{array}$ & 63.9 & 62.3 \\
\hline IL-6 & 0.674 & 0.004 & 263.3 & 69.4 & 60.7 \\
\hline PTX3 & 0.645 & 0.017 & 36.0 & 72.2 & 59.0 \\
\hline
\end{tabular}

AUC area under the curve, $C /$ confidence interval, IL-6 interleukin-6, PTX3 pentraxin 3 accordance with Sepsis-3 definitions [32]. This study enrolled patients from the ICU and did not assess the prognostic value of PTX3 in sepsis. According to Raija et al., high PTX3 levels at hospital admission predict severe sepsis and case fatality in patients with suspected infection [23]. However, in the current study, PTX3 was not a significant predictor of 28-day mortality in multivariate Cox regression analysis.

Our study showed that groups with high IL-6 and PTX3 levels have higher 28-day mortality than those with low IL-6 and PTX3, and these results were consistent with those reported by some other studies. Previous studies revealed that IL-6 is an independent predictor for mortality [18-20, 36]; one cohort study suggested that PTX3 levels at admission can predict 28-day mortality in a community-based hospital [38], and another study reported that PTX3 can predict 30-day and 6month mortality in patients with sepsis and septic shock during intensive care treatment [39]. A prior study reported that PTX3 levels were below $2 \mathrm{ng} / \mathrm{mL}$ in normal healthy persons [40]. In patients with bacteremia, increased PTX3 levels occur in the acute phase of infection and normalize on recovery [41]; we also found that PTX3 levels in patients with septic shock were initially high but normalized on recovery.

We found that the lactate level was an independent predictor of 28-day mortality in patients with sepsis and septic shock, although this marker was not the main focus of the current study. Some studies have reported that lactate levels can predict mortality in severe sepsis [18], and others have demonstrated that lactate is a significant prognostic marker that reflects hypoperfusion, particularly in critically ill patients [42, 43]. Although lactate is not an inflammatory cytokine, it can be used as a valuable prognostic marker in sepsis and septic shock.

The present study has some advantages. First, we performed a prospective controlled study of biomarkers among ED patients with sepsis and septic shock. Second, the research was conducted in accordance with the latest Sepsis-3 definitions. Third, both diagnostic and prognostic values of biomarkers were assessed. To the best of our knowledge, this is the first study to examine both the diagnostic and prognostic values of IL-6, PTX3, PCT, CRP, and lactate in sepsis and septic shock according to the Sepsis-3 definitions.

This study also had some limitations in that it was conducted in a single center at a tertiary referral teaching hospital, and we did not include patients who had infections but failed to meet the sepsis criteria. If these patients were included in the control group, the cut-off value for sepsis and septic shock may have increased. Further, some of the enrolled patients were transferred to our institution with prior sepsis management, including antibiotics, fluids, or vasopressors. 
Table 7 Studies on the Clinical Value of Biomarkers Including Interleukin-6 in Sepsis Patients

\begin{tabular}{|c|c|c|c|c|c|c|c|c|}
\hline $\begin{array}{l}\text { Author } \\
\text { [reference No.] } \\
\end{array}$ & Song et al. & $\begin{array}{l}\text { Takahashi } \\
\text { et al. [20] }\end{array}$ & $\begin{array}{l}\text { Behnes } \\
\text { et al. [35] }\end{array}$ & $\begin{array}{l}\text { Hamed } \\
\text { et al. [32] }\end{array}$ & $\begin{array}{l}\text { Harbarth } \\
\text { et al. [16] }\end{array}$ & $\begin{array}{l}\text { Jekarl } \\
\text { et al. [19] }\end{array}$ & $\begin{array}{l}\text { Mat-Nor } \\
\text { et al. [36] }\end{array}$ & $\begin{array}{l}\text { Miguel-Bayarri } \\
\text { et al. [18] }\end{array}$ \\
\hline Year of publication & 2019 & 2016 & 2014 & 2017 & 2001 & 2013 & 2016 & 2011 \\
\hline Definitions & Sepsis-3 & Sepsis-2 & Sepsis-2 & Sepsis-3 & Sepsis-2 & Sepsis-2 & Sepsis-2 & Sepsis-2 \\
\hline Setting & ED & $I C U$ & $\mathrm{ICU}$ & $I C U$ & $\mathrm{ICU}$ & ED & $\mathrm{ICU}$ & ICU \\
\hline Biomarkers & $\begin{array}{l}\text { IL-6, PTX3 } \\
\text { PCT, CRP }\end{array}$ & $\begin{array}{l}\text { IL-6, PCT, } \\
\text { presepsin, } \\
\text { CRP }\end{array}$ & $\begin{array}{l}\text { IL-6, PCT, } \\
\text { presepsin, CRP }\end{array}$ & $\begin{array}{l}\text { IL-6, PTX3, PCT, } \\
\text { CRP }\end{array}$ & $\begin{array}{l}\text { IL-6, } \\
\text { PCT, IL-8 }\end{array}$ & $\begin{array}{l}\text { IL-6, PCT, } \\
\text { CRP }\end{array}$ & IL-6, PCT & $\begin{array}{l}\text { IL-6, PCT, } \\
\text { CRP }\end{array}$ \\
\hline Case & Sepsis & $\begin{array}{l}\text { Severe sepsis, } \\
\text { septic shock }\end{array}$ & Septic shock & Sepsis & Sepsis & $\begin{array}{l}\text { Severe sepsis, } \\
\text { septic shock }\end{array}$ & Sepsis & $\begin{array}{l}\text { Severe sepsis, } \\
\text { septic shock }\end{array}$ \\
\hline Control & $\begin{array}{l}\text { Healthy } \\
\text { control, } \\
\text { Patient } \\
\text { control }\end{array}$ & $\begin{array}{l}\text { No infection } \\
\text { with organ } \\
\text { dysfunction }\end{array}$ & $\begin{array}{l}\text { Patient control, } \\
\text { SIRS, sepsis, } \\
\text { severe sepsis }\end{array}$ & $\begin{array}{l}\text { Healthy control, } \\
\text { patient control }\end{array}$ & SIRS & SIRS, sepsis & SIRS & - \\
\hline Diagnostic value & $\begin{array}{l}\text { IL-6> PTX3> } \\
\text { PCT > CRP }\end{array}$ & $\begin{array}{l}\mathrm{IL}-6>\mathrm{PCT}> \\
\mathrm{CRP}>\text { presepsin }\end{array}$ & $\begin{array}{l}\| \mathrm{L}-6>\mathrm{PCT}> \\
\text { presepsin }>\text { CRP }\end{array}$ & $\begin{array}{l}\mathrm{IL}-6=\mathrm{PTX} 3=\mathrm{PCT} \\
>\mathrm{CRP}\end{array}$ & $\begin{array}{l}\text { PCT }>\mathrm{IL}- \\
6>\mathrm{IL}-8\end{array}$ & $\begin{array}{l}\mathrm{PCT}>\mathrm{IL}-6> \\
\mathrm{CRP}\end{array}$ & $\begin{array}{l}\mathrm{PCT}>\mathrm{IL}- \\
6\end{array}$ & - \\
\hline $\begin{array}{l}\text { Most valuable } \\
\text { prognostic marker }\end{array}$ & IL-6 & IL-6 & - & - & - & IL-6 & - & $\| \mathrm{L}-6$ \\
\hline
\end{tabular}

ED emergency department, ICU intensive care unit, IL-6 interleukin-6, PTX3 pentraxin 3, PCT procalcitonin, CRP C-reactive protein

\section{Conclusions}

IL-6 and PTX3 can be used as both diagnostic and prognostic biomarkers for sepsis and septic shock diagnosed in accordance with the Sepsis-3 definitions. Overall, IL-6 was superior to PTX3 and PCT in both diagnostic and prognostic value for sepsis and septic shock. The results of this study should be verified by a prospective controlled multi-center study.

\section{Abbreviations}

APACHE: Acute physiology and chronic health evaluation; AUC: Area under the curve; $\mathrm{Cl}_{\text {: }}$ Confidence interval; CRP: C-reactive protein; ED: Emergency department; ICU: Intensive care unit; IL-6: Interleukin-6; IQR: Interquartile range.; PCT: Procalcitonin; PTX3: Pentraxin 3; qSOFA: quick Sequential organfailure assessment; SEM: Standard error of the mean

\section{Acknowledgments}

The authors thank research nurse Hye-Yoon Jung and researcher Min-Sook Jung for their contributions to the project. We also thank Jae-Hyung Cha, PhD for lending statistical support.

\section{Authors' contributions}

DWP and JS designed the study and were the major contributors in writing the manuscript. JS and JHP collected and analyzed the study data. SM and $\mathrm{HC}$ helped with planning and analyzing in the study. DWP and HS evaluated laboratory tests and participated in statistical analyses. JS and WSC controlled data accuracy. SM supervised the study and corrected the manuscript. All authors read and approved the final manuscript.

\section{Authors' information}

DWP and WSC are professors in the Division of Infectious Diseases, Department of Internal Medicine at Korea University Ansan Hospital, Ansan, Republic of Korea. JS and JHP are clinical assistant professors in the Department of Emergency Medicine at Korea University Ansan Hospital, Ansan, Republic of Korea. SM and HC are professors in the Department of Emergency Medicine at Korea University Ansan Hospital, Ansan, Republic of Korea. HS is a clinical assistant professor in the Division of Infectious Diseases, Department of Internal Medicine at Korea University Ansan Hospital, Ansan, Republic of Korea.

\section{Funding}

This work was supported by Korea University Ansan Hospital [grant numbers 01700641, K1722241]. The funder had no role in the design of the study, the collection, analysis, and interpretation of data and in writing the manuscript.

\section{Availability of data and materials}

The datasets supporting the conclusions of this article are available from the corresponding author on reasonable request.

\section{Ethics approval and consent to participate}

We have presented similar work (only abstract) at the Sepsis 2019 Conference: https://icm-experimental.springeropen.com/articles/10.1186/s40635019-0254-1?opt/n=false. This study complied with the provisions of the Declaration of Helsinki and was approved by the institutional review board (IRB) of Korea University Medical Center (IRB No. 2017AS0415). We included only adults ( $\geq 18$ years old) who provided written informed consent for the acquisition of biomarker samples. We obtained written informed consent from the legal representatives of patients who were unable to provide consent to participate in the study due to decreased mental capacity.

\section{Consent for publication}

Not applicable.

\section{Competing interests}

The authors declare that they have no competing interests.

\section{Author details}

${ }^{1}$ Department of Emergency Medicine, Korea University Ansan Hospital, Ansan, Republic of Korea. 'Division of Infectious Diseases, Department of Internal Medicine, Korea University Ansan Hospital, 123, Jeokgeum-ro, Danwon-gu, Ansan-si, Gyeonggi-do, Republic of Korea.

Received: 7 August 2019 Accepted: 4 November 2019

Published online: 12 November 2019

\section{References}

1. Singer M, Deutschman CS, Seymour CW, Shankar-Hari M, Annane D, Bauer $M$, et al. The third international consensus definitions for Sepsis and septic shock (Sepsis-3). JAMA. 2016;315(8):801-10.

2. Rhodes A, Evans LE, Alhazzani W, Levy MM, Antonelli M, Ferrer R, et al. Surviving Sepsis campaign: international guidelines for Management of Sepsis and Septic Shock: 2016. Crit Care Med. 2017;45(3):486-552.

3. Angus DC, van der Poll T. Severe sepsis and septic shock. N Engl J Med. 2013;369(9):840-51. 
4. Shankar-Hari M, Phillips GS, Levy ML, Seymour CW, Liu VX, Deutschman CS, et al. Developing a new definition and assessing new clinical criteria for septic shock: for the third international consensus definitions for Sepsis and septic shock (Sepsis-3). JAMA. 2016;315(8):775-87.

5. De Backer D, Dorman T. Surviving Sepsis guidelines: a continuous move toward better Care of Patients with Sepsis. JAMA. 2017;317(8):807-8.

6. Biron BM, Ayala A, Lomas-Neira JL. Biomarkers for Sepsis: what is and what might be? Biomark Insights. 2015;10(Suppl 4):7-17.

7. Silvestre J, Póvoa P, Coelho L, Almeida E, Moreira P, Fernandes A, et al. Is Creactive protein a good prognostic marker in septic patients? Intensive Care Med. 2009;35(5):909-13.

8. Póvoa P, Coelho L, Almeida E, Fernandes A, Mealha R, Moreira P, et al. Creactive protein as a marker of infection in critically ill patients. Clin Microbiol Infect. 2005;11(2):101-8.

9. Nakamura A, Wada H, Ikejiri M, Hatada T, Sakurai H, Matsushima Y, et al. Efficacy of procalcitonin in the early diagnosis of bacterial infections in a critical care unit. Shock. 2009:31(6):586-91.

10. Kibe $S$, Adams K, Barlow G. Diagnostic and prognostic biomarkers of sepsis in critical care. J Antimicrob Chemother. 2011;66 Suppl 2:ii33-40.

11. Henriquez-Camacho C, Losa J. Biomarkers for sepsis. Biomed Res Int. 2014; 2014:547818.

12. $M a L$, Zhang $H$, Yin $Y L$, Guo $W Z$, Ma $Y Q$, Wang $Y B$, et al. Role of interleukin-6 to differentiate sepsis from non-infectious systemic inflammatory response syndrome. Cytokine. 2016;88:126-35.

13. Spittler A, Razenberger M, Kupper H, Kaul M, Hackl W, Boltz-Nitulescu G, et al. Relationship between interleukin- 6 plasma concentration in patients with sepsis, monocyte phenotype, monocyte phagocytic properties, and cytokine production. Clin Infect Dis. 2000;31(6):1338-42.

14. Patel RT, Deen KI, Youngs D, Warwick J, Keighley MR. Interleukin 6 is a prognostic indicator of outcome in severe intra-abdominal sepsis. Br J Surg. 1994;81(9):1306-8.

15. Gårdlund B, Sjölin J, Nilsson A, Roll M, Wickerts CJ, Wretlind B. Plasma levels of cytokines in primary septic shock in humans: correlation with disease severity. J Infect Dis. 1995;172(1):296-301.

16. Harbarth S, Holeckova K, Froidevaux C, Pittet D, Ricou B, Grau GE, et al. Diagnostic value of procalcitonin, interleukin-6, and interleukin-8 in critically ill patients admitted with suspected sepsis. Am J Respir Crit Care Med. 2001; 164(3):396-402.

17. Pettilä V, Hynninen M, Takkunen $O$, Kuusela P, Valtonen M. Predictive value of procalcitonin and interleukin 6 in critically ill patients with suspected sepsis. Intensive Care Med. 2002;28(9):1220-5.

18. Miguel-Bayarri V, Casanoves-Laparra EB, Pallás-Beneyto L, Sancho-Chinesta S, Martín-Osorio LF, Tormo-Calandin C, et al. Prognostic value of the biomarkers procalcitonin, interleukin-6 and C-reactive protein in severe sepsis. Med Int. 2012;36(8):556-62.

19. Jekarl DW, Lee SY, Lee J, Park YJ, Kim Y, Park JH, et al. Procalcitonin as a diagnostic marker and IL-6 as a prognostic marker for sepsis. Diagn Microbiol Infect Dis. 2013;75(4):342-7.

20. Takahashi W, Nakada TA, Yazaki M, Oda S. Interleukin-6 levels act as a diagnostic marker for infection and a prognostic marker in patients with organ dysfunction in intensive care units. Shock. 2016;46(3):254-60.

21. Mantovani A, Garlanda C, Doni A, Bottazzi B. Pentraxins in innate immunity: from C-reactive protein to the long pentraxin PTX3. J Clin Immunol. 2008; 28(1):1-13.

22. Garlanda C, Bottazzi B, Bastone A, Mantovani A. Pentraxins at the crossroads between innate immunity, inflammation, matrix deposition, and female fertility. Annu Rev Immunol. 2005;23:337-66.

23. Uusitalo-Seppälä R, Huttunen R, Aittoniemi J, Koskinen P, Leino A, Vahlberg $T$, et al. Pentraxin 3 (PTX3) is associated with severe sepsis and fatal disease in emergency room patients with suspected infection: a prospective cohort study. PLoS One. 2013;8(1):e53661.

24. Mauri T, Bellani G, Patroniti N, Coppadoro A, Peri G, Cuccovillo I, et al. Persisting high levels of plasma pentraxin 3 over the first days after severe sepsis and septic shock onset are associated with mortality. Intensive Care Med. 2010;36(4):621-9.

25. Liu S, Qu X, Liu F, Wang C. Pentraxin 3 as a prognostic biomarker in patients with systemic inflammation or infection. Mediat Inflamm. 2014; 2014:421429.

26. Kim SB, Lee KH, Lee JU, Ann HW, Ahn JY, Jeon YD, et al. Long Pentraxin 3 as a predictive marker of mortality in severe septic patients who received successful early goal-directed therapy. Yonsei Med J. 2017;58(2):370-9.
27. Jie H, Li Y, Pu X, Ye J. Pentraxin 3, a predicator for 28-day mortality in patients with septic shock. Am J Med Sci. 2017;353(3):242-6.

28. Hu C, Zhou Y, Liu C, Kang Y. Pentraxin-3, procalcitonin and lactate as prognostic markers in patients with sepsis and septic shock. Oncotarget. 2018;9(4):5125-36

29. Cuello F, Shankar-Hari M, Mayr U, Yin X, Marshall M, Suna G, et al. Redox state of pentraxin 3 as a novel biomarker for resolution of inflammation and survival in sepsis. Mol Cell Proteomics. 2014;13(10):2545-57.

30. Caironi P, Masson S, Mauri T, Bottazzi B, Leone R, Magnoli M, et al. Pentraxin 3 in patients with severe sepsis or shock: the ALBIOS trial. Eur J Clin Investig. 2017:47(1):73-83.

31. Lee YT, Gong M, Chau A, Wong WT, Bazoukis G, Wong SH, et al. Pentraxin-3 as a marker of sepsis severity and predictor of mortality outcomes: a systematic review and meta-analysis. J Inf Secur. 2018;76(1):1-10.

32. Hamed S, Behnes M, Pauly D, Lepiorz D, Barre M, Becher T, et al. Diagnostic value of Pentraxin-3 in patients with sepsis and septic shock in accordance with latest sepsis-3 definitions. BMC Infect Dis. 2017;17(1):554.

33. Knaus WA, Draper EA, Wagner DP, Zimmerman JE. APACHE II: a severity of disease classification system. Crit Care Med. 1985;13(10):818-29.

34. Vincent JL, Moreno R, Takala J, Willatts S, De Mendonca A, Bruining H, et al. The SOFA (Sepsis-related organ failure assessment) score to describe organ dysfunction/failure. On behalf of the working group on Sepsis-related problems of the European Society of Intensive Care Medicine. Intensive Care Med. 1996;22(7):707-10

35. Behnes M, Bertsch T, Lepiorz D, Lang S, Trinkmann F, Brueckmann M, et al. Diagnostic and prognostic utility of soluble CD 14 subtype (presepsin) for severe sepsis and septic shock during the first week of intensive care treatment. Crit Care. 2014;18(5):507.

36. Mat-Nor MB, Md Ralib A, Abdulah NZ, Pickering JW. The diagnostic ability of procalcitonin and interleukin-6 to differentiate infectious from noninfectious systemic inflammatory response syndrome and to predict mortality. J Crit Care. 2016;33:245-51.

37. Uusitalo-Seppälä R, Koskinen $\mathrm{P}$, Leino A, Peuravuori H, Vahlberg T, Rintala EM. Early detection of severe sepsis in the emergency room: diagnostic value of plasma C-reactive protein, procalcitonin, and interleukin-6. Scand J Infect Dis. 2011;43(11-12):883-90.

38. Bastrup-Birk S, Munthe-Fog L, Skjoedt MO, Ma YJ, Nielsen H, Køber L, et al. Pentraxin-3 level at admission is a strong predictor of short-term mortality in a community-based hospital setting. J Intern Med. 2015;277(5):562-72.

39. Hamed S, Behnes M, Pauly D, Lepiorz D, Barre M, Becher T, et al. Pentraxin-3 predicts short- and mid-term mortality in patients with Sepsis and septic shock during intensive care treatment. Clin Lab. 2018;64(6):999-1011.

40. Yamasaki K, Kurimura M, Kasai T, Sagara M, Kodama T, Inoue K. Determination of physiological plasma pentraxin 3 (PTX3) levels in healthy populations. Clin Chem Lab Med. 2009;47(4):471-7.

41. Huttunen R, Hurme M, Aittoniemi J, Huhtala H, Vuento R, Laine J, et al. High plasma level of long pentraxin 3 (PTX3) is associated with fatal disease in bacteremic patients: a prospective cohort study. PLoS One. 2011;6(3): e17653.

42. Khosravani H, Shahpori R, Stelfox HT, Kirkpatrick AW, Laupland KB. Occurrence and adverse effect on outcome of hyperlactatemia in the critically ill. Crit Care. 2009;13(3):R90.

43. Soliman HM, Vincent JL. Prognostic value of admission serum lactate concentrations in intensive care unit patients. Acta Clin Belg. 2010;65(3): $176-81$.

\section{Publisher's Note}

Springer Nature remains neutral with regard to jurisdictional claims in published maps and institutional affiliations. 